\title{
GIS-based Assessment of Vulnerability to Landslide Hazards in Lushan Earthquake-stricken Areas
}

\author{
Mingtao Ding*, Cheng Miao \\ School of Environment and Resource, Southwest University of Science and Technology \\ Mianyang 621010, China \\ *E-mail: mingtaoding@163.com
}

Received 11 April 2015

Accepted 28 May 2015

\begin{abstract}
This paper establishes a GIS-based system of vulnerability assessment to landslide hazard for Lushan earthquake-stricken areas. By taking these areas as the study area and ArcGIS 9.3 Software as the platform; with GIS Grid Technology and adopting Contributing Weight Overlay Model, we extract 6 vulnerability assessment indexes including population, economic, and road densities, building and forestland coverage, and landslide hazard affected areas. Besides, it compiles vulnerability zoning maps to landslide hazard by means of Natural Breaks Classification. The results show that the high, middle, and low vulnerability zones occupy $17.93 \%, 61.54 \%$, and $20.53 \%$ of the total area respectively. The vulnerability level is positively correlated with the former four indexes; while negatively with the forest coverage. The distribution of landslide hazard affected areas is closely correlated to the intensity of human engineering activities. Contrasted with the field survey ones, the GIS-based zoning results of vulnerability to landslide hazard basically correspond with the actual situation of Lushan earthquake-stricken areas, and can thus be applied in guiding the post-disaster restoration and construction, settlement relocation, and population distribution readjustment.
\end{abstract}

Keywords: Landslide, vulnerability assessment, Contributing Weight Overlay Model, Lushan earthquake-stricken areas

\section{Introduction}

In recent years, important research projects on vulnerability have been provided by more and more international scientific programs and organizations (such as IHDP, IPCC, IGBP, etc.). Such research has aroused wide concern, especially in global environmental changes and sustainable scientific fields; and has thus become a principal analysis tool (Yang Gui-shan et al., 2000; Gutter et al., 2003). Concerning the subject matter of hazard vulnerability, exploratory research has been made by many foreign scholars. Among them, Blaikie (1994) argued that it was produced by men in pursuing economic, environmental, social, political, and personal properties; while Burton (1993) reckoned that it would be influenced by production activities, social systems, social groups, family structures, age structures, races, historical background, physical and mental health, etc. Domestic scholars also carried out relative research (Zhang Ye-cheng et al., 1995). Jiang Tong (1996) put forward for the first time the complete concept of social vulnerability. $\mathrm{He}$ further elucidated its connotation, emphasized its importance in hazard assessment, and briefly analyzed its relationship with natural vulnerability. Guo Yue (2005) summarized current national and international studies on social vulnerability to natural hazards by generalizing the theories, methods, and principles applied. Tang Chuan (2005) took "population density in counties and county-level cities, house assets, GDP, arable land percentage, highway distribution" as indexes for landslide risk assessment when he compiled the landslide hazard map of Red River drainage area. Liu Xi-lin (2003), 
in the landslide risk assessment survey, presented computing formulas for human and property vulnerabilities. Furthermore, he studied regional and single-gully debris flows respectively. Based on the flood vulnerability assessment for Dongting Lake Region, Gao Ji-xi and his co-researchers (2004) believed that the regional flood vulnerability depends on hazard-triggering factors, hazard-forming environment, hazard-bearing substance, and social hazard reduction abilities. They furthered the study by quantitative computation.

However, landslide hazard vulnerability has seldom been studied (Alexander et al., 1999, 2005; Fell, 1994, 2005; Fell and Hartford, 1997; Lee and Jones, 2004; Glade, 2004; Copons R., 2005; Leone F., 1996; Msilimba and Holmes, 2005). Instead of regional ones, the few studies mainly concentrated on the vulnerability of typical landslides (Mirco Galli and Fausto Guzzetti, 2007; Xiang Xi-qiong, 2005). Some scholars even considered it improper to involve regional vulnerability in landslide hazard research (Dai et al., 2002). Despite all this, there have been scholars carrying out significant research on relative concepts and assessment methods of landslide hazard vulnerability. Mario Mejiar-navarro and Ellen E. Woh (1994) analyzed the geological hazard susceptibility, land and life vulnerabilities of Municipio de Medellín in Colombia. They also made risk assessment zoning maps by combining analysis results through GIS Technology. Michael-Leiba (2002) carried out landslide vulnerability analysis of inhabitants, buildings, and roads in City of Cairn, Australia. Vandine (2004) believed that the landslide vulnerability is resulted from either stability or fragileness of a certain element; potential destructive power of a landslide or the resistance to it. In the risk prediction for landslide hazards in the new Badong county seat, Wu Yi-ping (2004) and his co-researchers took "building, road, and lifeline engineering, population distribution, and land use types" as vulnerability assessment factors. Jin Jiang-jun (2007) presented an assessment method of landslide hazard vulnerability based on land use types. Accordingly, an index system of hazard prevention and reduction abilities was established; specific assessment methods also provided. Shi Li-li (2009) accomplished regional landslide vulnerability assessment for the study area of Miyi County in Sichuan with Contributing Weight Overlay. She also finished vulnerability zoning and mapping through ArcGIS.

Based on the existing research (Ding and $\mathrm{Hu}, 2014$; Ding et al., 2014,2015; Miao and Ding, 2015), This paper sets up a vulnerability assessment system for landslide hazards in Lushan earthquake-stricken areas by using ArcGIS 9.3 Platform, GIS Grid Technology, and Contributing Weight Overlay Model. It also carries out vulnerability zoning research and guides local settlement relocation, population distribution, and management of hazard prevention and reduction.

\section{Study Area}

A 7.0-magnitude earthquake hit Lushan County $\left(30.3^{\circ} \mathrm{N}\right.$, $103.0^{\circ} \mathrm{E}$ ) of Ya'an City in Sichuan Province, China at 8:02 on April 20, 2013. The focal depth was $13 \mathrm{~km}$. According to the website of China Earthquake Administration, this powerful earthquake had caused 196 people dead, 21 missing, and 11,470 injured by 14:30, April 24. Lushan is a typical ecologically-vulnerable and secondary mountain hazard prone area. Especially since the April $20^{\text {th }}$ Earthquake, secondary mountain hazards have been occurring with higher frequency and greater scales, resulting in more severe losses.

The earthquake struck 21 counties (county-level cities and districts) at $29^{\circ} 28^{\prime} \sim 30^{\circ} 56^{\prime} \mathrm{N}$ and $102^{\circ} 16^{\prime} \sim 103^{\circ} 11^{\prime}$ E, including Lushan County, Baoxing County, and Tianquan County. The total area reaches $42,786.05 \mathrm{k} \mathrm{m}^{2}$ (Fig.1.). Located at the west edge of Sichuan Basin, the study area serves as a transition zone between the basin and the Qinghai-Tibetan Plateau.

\subsection{Topography and geomorphology}

Lying at the west edge of Sichuan Basin and the south section of Longmenshan, it is the transition zone between the First and the Second Ladder-like Regions (the Sichuan Basin and the Qinghai-Tibetan Plateau). As a whole, it is high in the north and west, and low in the south and east (Fig. 1). Covering the west Sichuan alpine and plateau area, the east basin and mountain area, it is defined by mountainous terrain (93.91\%). Its average elevation exceeds $1,300 \mathrm{~m}$, with the highest peak of 7,556 $\mathrm{m}$. Gonggashan at the southeast edge of Kangding County has an elevation difference (between the mountain summit and valley bottom) of more than 3,500 $\mathrm{m}$. Due to its complicated terrain, Gongga demonstrates clear vertical distribution of biological climate belts with well-grown plants and animals. In the northwest part of severely earthquake-stricken areas, Mount Erlang and Mount Jiajin of the Qionglaishan Range are situated. The former has a NE anticline and a SN distributed ridge; 


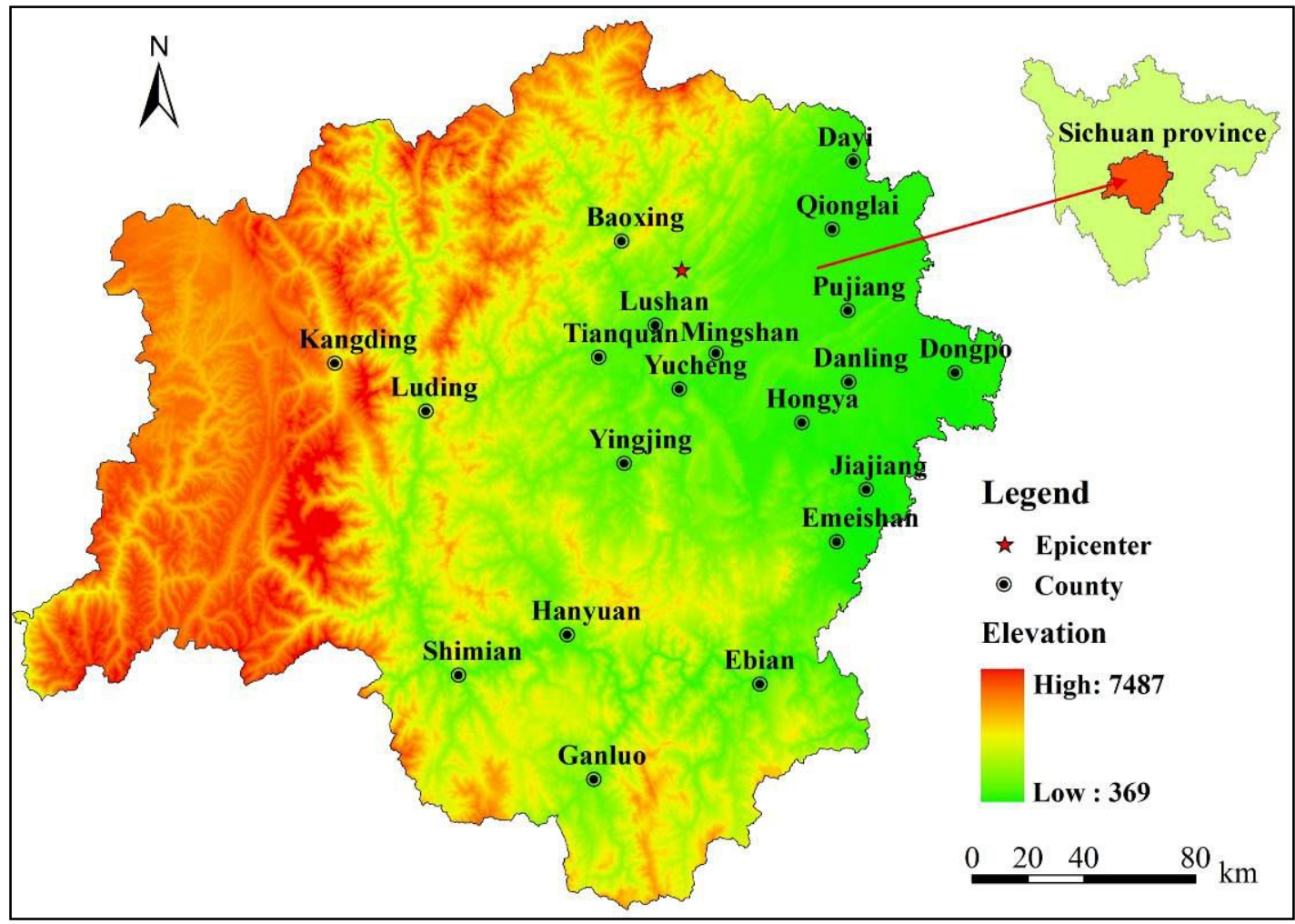

Fig.1. Location and DEM map of the study area

while the latter is $\mathrm{SN}$ oriented, with an elevation over $4,000 \mathrm{~m}$. Nibashan in the south part is NW oriented and higher than 3,000 $\mathrm{m}$; low mountains and hilly regions in the east define the terrain there.

\subsection{Stratigraphic lithology}

The Baoxing-Lushan-Ya'an Region is located in the joint area between the Longmenshan nappe structural belt and the west Sichuan Foreland Basin. It has various rock types and well-exposed Sinian, Ordovician, Silurian, Devonian, Permian, Triassic, Jurassic, Cretaceous, Paleogene, and Quaternary strata.

"Baoxing Rock Complex", i.e. magmatic rocks, is widely distributed in the Baoxing-Lushan Region. Rocks including gabbro, diorite, monzonitic granite, granite diorite, K-feldspar granite, and a small quantity of quartz diorite are contained in the complex.

\subsection{Geological structure}

The Baoxing-Lushan-Ya'an Region covers two structural units: the south section of Longmenshan nappe structural belt and the west edge of Sichuan Basin. The former can be divided into 4 sub-belts by the huge NE oriented faults: (1) Longdong fold nappe structural belt, (2) Baoxing thrust nappe structural belt, (3) Zhonglin-Shuangshi thin-skinned nappe structural belt, (4) Foreland fold structural belt.

\subsection{Meteorology and hydrology}

With the humid subtropical monsoon climate, it is warm in winter and cool in summer. The mean annual temperature ranges from $14.1{ }^{\circ} \mathrm{C}$ to $15.3^{\circ} \mathrm{C}$. The lowest average monthly temperature is in January, reaching $4^{\circ} \mathrm{C}$; and the highest in July, $23 \sim 28^{\circ} \mathrm{C}$. The frost free period can last for 319 days. Great cloudiness, humidity, and rainfall intensity easily trigger floods. Gentle wind in rainy nights and scarce sunshine through thin fogs add unique features to this area, which is nicknamed as "Stagnant Area" for the terrain-induced poor air flow.

With abundant rainfall (over 1,700 mm/year), it ranks among the 4 rainstorm regions in Sichuan. Concerning spatial distribution, a northwest-to-southeast increase in rainfall is witnessed. For many years, the mean annual rainfall in Baoxing and Lushan is about $800 \sim 1,200 \mathrm{~mm}$; and that in Yingjing and Tianquan, 1,400 1,800 mm. 
The mean annual rainfall measured at the Precipitation Station of Erlang Mountain in Tianquan County is 2,041.7 $\mathrm{mm}$; and that at the Jinshan Station in Yingjing County 2,637 mm, ranking top in Sichuan.

The study area is located in the upper reaches of Qingyi River and covered with dense vegetation. The runoff has precipitation as its main source and snowmelt as the second. Affected by the terrain, rivers there run from northwest to southeast. Major ones include Baoxing, Lushan, Yuxi, and Tianquan, all of which are characterized by shoals and rapids.

\subsection{Landslide hazards}

It has been confirmed, through field survey and analytic interpretation of remote sensing images, that 690 landslide hazard sites have been developed in the study area, concentrating along the south section of Longmenshan earthquake fault belt (triggering seismic fault of Lushan Earthquake-Yingxiu-Baoxing-Luding fault); and along steep valley slopes, especially those near the Lingguan River.

\section{Vulnerability Assessment}

\subsection{Assessment model}

Contributing Weight Overlay has been adopted as the model of landslide hazard vulnerability assessment in this study. This model was initiated in 2004 by Qiao Jian-ping, a researcher in Chengdu Institute of Mountain Hazards and Environment, Chinese Academy of Sciences (Qiao Jian-ping, 2004). Being developed and improved, it has been applied in various fields and achieved good results (Wang Meng, 2008, 2010; Shi Li-li, 2009).

It means to multiply the self-weight and the mutual weight (of index factors for landslide hazard vulnerability assessment) by contributing rate and overlay them:

$$
V=\stackrel{o}{r} U_{o i} w_{i f} w_{i}^{\prime} \quad(i=1,2, \ldots n, f=h, m, l)
$$

In the formula: $\mathrm{V}$-landslide hazard vulnerability, $\stackrel{o}{r}$ —sign of the summation for rows, $U_{o i}$-contributing rate of the assessment sample, $w_{i f}$-self-weight of factors, $w_{i}^{\prime}-$ mutual weight of factors.

\subsubsection{Quantification of indexes}

The indexes are divided into different intervals according to certain criteria (for example, the criterion of standard deviation). The number of landslides in each interval and its percentage are calculated. The contribution to the regional vulnerability by landslide hazards can be expressed as:

$$
U_{i}^{\prime \prime}=U_{i}^{\prime \prime}(S)
$$

In the formula:

$U_{i}^{\prime \prime}$ - vulnerability factor set,

$S$ - number of landslides in the vulnerability factor.

\subsubsection{Assessment on contributing rate}

Contributing Weight Overlay Model is applied in quantitatively analyzing vulnerability factors' contribution to landslide bearers' loss. The contributing rate of each factor is the basis of such analysis; the self and the mutual weight, the result.

The contributing index of landslide hazards to each regional vulnerability factor is computed:

$$
U_{o i}^{\prime}=\frac{U_{i}^{\prime \prime}}{m}
$$

In the formula:

$$
\begin{aligned}
& U_{o i}^{\prime} \text {-contributing index, } \\
& U_{i}^{\prime \prime} \text {-vulnerability factor set, } \\
& m \text {-number of influencing factors to }
\end{aligned}
$$

vulnerability by landslide hazards.

The contributing rate is then computed:

$$
U_{o i}=\frac{U_{o i}^{\prime}}{\sum U_{o i}^{\prime}}
$$

Formula (4) can be extended by substituting (2) and (3) into it:

$$
U_{o i}(\%)=\frac{U_{i}^{\prime \prime}(S) / M}{\sum U_{i}^{\prime \prime}(S) / M} \times 100 \%
$$

The extreme value of contributing rate is obtained:

$$
y_{i}=\frac{x_{i}-x_{\min }}{x_{\max }-x_{\min }}
$$

In the formula: 
$y_{i}$ - normalized value of the index,

$x_{i}$-value of a certain grid index,

$x_{\mathrm{min}}$ - the minimum index value,

$x_{\max }$ - the maximum index value.

\subsubsection{Computation of weight}

Weight refers to the relative importance granted to an index in the entire assessment system. With the method of Contributing Weight, its computation process is composed of 3 steps:

The first step: equalization

Sampling in line with Formula (5) results in 3 levels of contributing rate: the high, middle, and low.

$$
d=\frac{\left(U_{o i \max }-U_{o i \min }\right)}{3}
$$

In the high: $X_{1}=\left(a_{1} \sim a_{2}\right)$, middle: $X_{2}=\left(a_{2} \sim a_{3}\right)$, and low $X_{3}=\left(a_{3} \sim a_{4}\right)$ contributing rate intervals, $a_{1}=U_{o i \max }, a_{2}=a_{1}-d, a_{3}=U_{o i \min }+d$, and $a_{4}=U_{o i \min }$.

Being graded, each vulnerability factor is equalized:

$$
\bar{U}_{o i}=\left[\begin{array}{l}
\overline{H U_{o i}} \\
\frac{M U_{o i}}{L U_{o i}}
\end{array}\right]=\left[\begin{array}{l}
\frac{\sum H U_{o i}}{N} \\
\frac{\sum M U_{o i}}{N} \\
\frac{\sum U_{o i}}{N}
\end{array}\right]
$$

In the formula: $\bar{U}_{o i}$-equalization result,

$\overline{H U_{o i}}$ - mean value of high contributing rates, $\overline{M U_{o i}}$ - mean value of middle contributing rates, $\overline{L U_{o i}}$ - mean value of low contributing rates, $H U_{o i}$ - high contributing rate, $M U_{o i}$-middle contributing rate, $L U_{o i}$ - low contributing rate, $\mathrm{N}$-number of contributing rate indexes at different levels.

The second step: self-weight

It refers to the contributing rate of landslide hazards to vulnerability within a factor's internal intervals with different levels and densities. Its computation formula is:

$$
w_{i}^{\prime}=\frac{\bar{U}_{o i}}{\sum \bar{U}_{o i}}
$$

In the formula: $w_{i}^{\prime}-$ self-weight of the factor,

$$
\bar{U}_{o_{i}} \text {-equalization result. }
$$

The third step: mutual weight

It is the weight value between different factors, representing each factor's contribution to the vulnerability of study area. This model gives full consideration to the contributing effect of factors. Therefore, besides the internal weight of each individual factor, the inter-factor weight relationship and multiple index weight of the factor are obtained. The computation method is as follows:

The summation of contributing rates at different levels in Formula (8) is obtained for rows:

$$
R_{i f}=\stackrel{o}{r} U_{o i f} \quad(i=1,2 \ldots n, f=h, m, l)
$$

In the formula: $\stackrel{o}{r}$ - sign of the summation for rows,

$$
R_{i f} \text { - series grading and summation of }
$$
the $\mathrm{i}^{\text {th }}$ factor's contributing rate.

By normalizing contributing rates of the same level, each factor's weight in contributing rates of different levels can be obtained:

$$
R_{i f}^{\prime}=\frac{R_{i f}}{r R_{i f}} \quad(\mathrm{i}=1,2 \ldots \mathrm{n}, f=h, m, l)
$$

In the formula: $R_{i f}^{\prime}$-normalization series of contributing rates at different levels.

The summation for rows of each factor's $R_{i f}^{\prime}$ in Formula (11) can be then obtained:

$$
D_{i}=\stackrel{o}{r} R_{i f}^{\prime}
$$

Through the normalization of Formula (12), the mutual weight of contributing rates can be obtained:

$$
w_{i}^{\prime}=D_{i} / \stackrel{o}{r} D_{i}
$$

In the formula: $w_{i}^{\prime}-$ mutual weight of contributing rates $\left(w_{i}^{\prime}<1\right)$.

\subsection{Assessment unit}

The total study area of $42,786 \mathrm{~km}^{2}$ has been divided into 
40,777 assessment units through Grid-oriented Vector Data Processing. Each unit area is $1 \mathrm{~km} \times 1 \mathrm{~km}$.

\subsection{Assessment indexes}

The assessment index system for landslide hazards in Lushan earthquake-stricken areas has been established in line with the principle of being scientific, systematic, comparative, regional, and easy to operate. In such process, elements like limited access to resources are also taken into consideration. A total of 6 factors are selected as assessment indexes: population density, economic density, forestland coverage, building coverage, road density, and landslide hazard affected areas.

(1) Population density

It refers to the population per unit area:

$$
D=P \mathrm{i} / S_{i}
$$

In the formula: $\mathrm{D}$ - population density, $P \mathrm{i}$-population within Region $i, S_{i}$ - area of Region $i$

The vulnerability is closely correlated with population density. The larger the latter is, the greater the former. It is also correlated with population quality. Elements such as genders, ages, physical conditions, professional features, educational attainment, social status, and national characteristics of a population exert influence on people's ability to prevent, handle, and resist hazards. Generally speaking, the elderly, women, children, and people with poor physical condition are groups vulnerable to natural hazards.

Therefore, this index should be modified so as to be fully utilized. In this paper, 3 modifiers are adopted: population ratios of people older than 60 and younger than 16, women, and agricultural people. The modified population density provides information of both population quantity and quality:

$$
D_{R}=D \times(a+b+c) / 3
$$

In the formula: $D_{R}$-modified population density, D-original population density, $a$-population ratio of people older than 60 and younger than $16, b$-population ratio of women, $c$-population ratio of agricultural people.

(2) Economic density

It refers to the GDP-RA (regional area) ratio, indicating the effect of economic activities and the intensity of land use in the unit urban area. The larger it is, the greater the social vulnerability.

(3) Forestland coverage

It's the forestland area per unit regional area, indicating the condition of local natural environment.

(4) Building coverage

Buildings are susceptible to landslide hazards as well. The building area used in this paper is extracted from the SPOT data, referring to the gross base area of all the buildings in the study area. Accordingly, the ratio of building area over total area can reflect the concentration degree of buildings.

(5) Road density

Like the building area, the road length is also extracted from the SPOT data. Being divided by the total area, it yields the road density, an index indicating the concentration degree of roads. The larger this index is; the higher the susceptibility to landslide hazards.

(6) Landslide hazard affected areas

A buffer zone with a $1 \mathrm{~km}$ radius is set up for computing the influence scope of each landslide hazard site, which is acquired from field survey and remote sensing images.

\subsection{Data processing and assessment results}

Elementary data used in this paper come from 3 sources: (1) road and building distribution data extracted from Landsat ETM+ images of the study area, (2) elementary data of social and economic statistics, topography and geomorphology, land use, earthquake, etc. provided by the Earth System Scientific Data Sharing Platform (the thematic database of Lushan Earthquake relief, http://www.geodata.cn/extra/TopicsWin/?isCookieChecke $\mathrm{d}=$ true), one of the National Science and Technology Infrastructure Platforms, (3) data obtained through field survey and analytic interpretation of remote sensing images. And the attributes of research data are described in the existing research (Miao et al. 2014; Miao and Ding, 2015).In the phase of quantitative assessment, all the index data are expressed in the form of density. The reason is threefold. Firstly, density is the number of a certain element within a unit area; it can thus be regarded as a continuous variable. Secondly, it is a kind of spatial data correlated with the size and location of study area. Thirdly, the density expression thus helps the regionalization of vulnerability indexes and the 
realization of ArcGIS-based sampling.

Based on GIS and Grid technologies, the procedure of landslide hazard vulnerability assessment is as follows: dividing the 6 index factor maps into grids, with an area of $1 \mathrm{~km} \times 1 \mathrm{~km}$ each; computing the factor value in every grid; using field calculator to gain the dimensionless factor value and quantitative index factor distribution maps (Fig 2-A 2-F); combining the maps into one and adding quantitative indexes onto it, so as to obtain a new map with the quantitative indexes of all 6 factors; deriving attributes of the map into a DBF file of data sheet; and computing self and mutual weights of the index factors by Excel (Table 1.). It can be seen from Table 1 that, in terms of weight, the order of vulnerability indexes is: building coverage $>$ population density $>$ economic density $>$ forestland coverage $>$ road density $>$ landslide hazard affected areas. The final step of the procedure: using the map to add self and mutual weights of all quantitative indexes into the attribute sheet, multiplying them by the contributing rate (Fig. 3-A 3-F), overlying them in the map (Formula 1); and obtaining the vulnerability zoning results of landslide hazards in Lushan earthquake-stricken areas. In compiling the final vulnerability zoning map (Fig. 4), this study utilizes the grading results gained through the method of Natural Break Classification. The results (Table 2.) show that the area percentage of high, middle, and low vulnerability zones is $17.93 \%, 61.54 \%$, and $20.53 \%$ respectively.

\section{Conclusion and Discussion}

\subsection{Conclusion}

Combining the field survey of study area with the analytic interpretation of remote sensing images, a conclusion can be drawn as follows:

(1) According to the vulnerability assessment results (Fig.4.), landslide hazard vulnerabilities in the study area demonstrate notable regional differences and features. By contrasting assessment index distribution maps of zones with different vulnerability levels (Fig.2.), a positive correlation is witnessed between the vulnerability level and population density, economic density, road density, and building coverage. In other words, the high vulnerability zone has a high population density, sound transport accessibility, densely concentrated buildings, and a developed economy. A negative correlation is between the forestland coverage and the vulnerability level, exposing the ecological fragileness of high vulnerability zone. On the contrary, the ecological environment of low vulnerability region is good. The middle vulnerability zone has the highest forestland coverage, highlighting its role as the principle forestland and field husbandry zone of the study area.

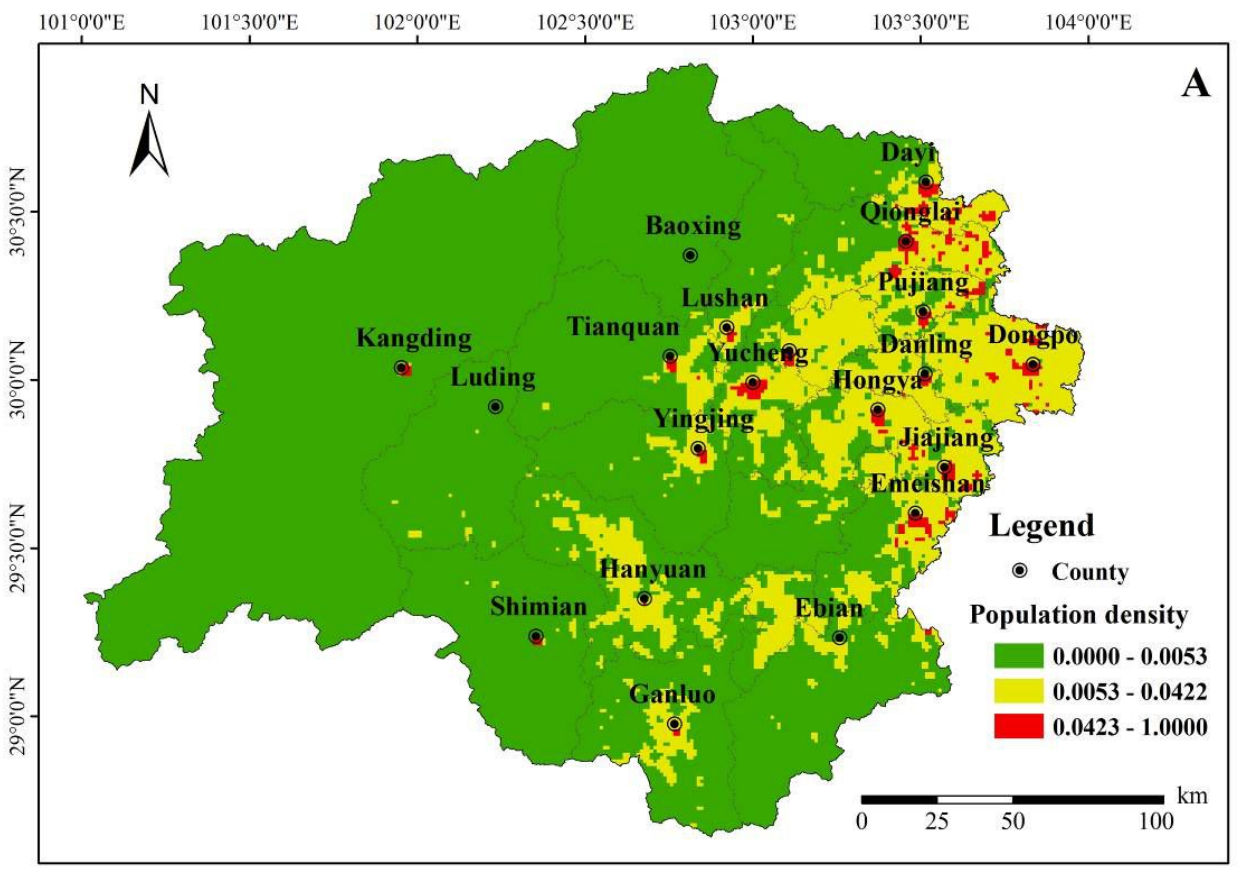



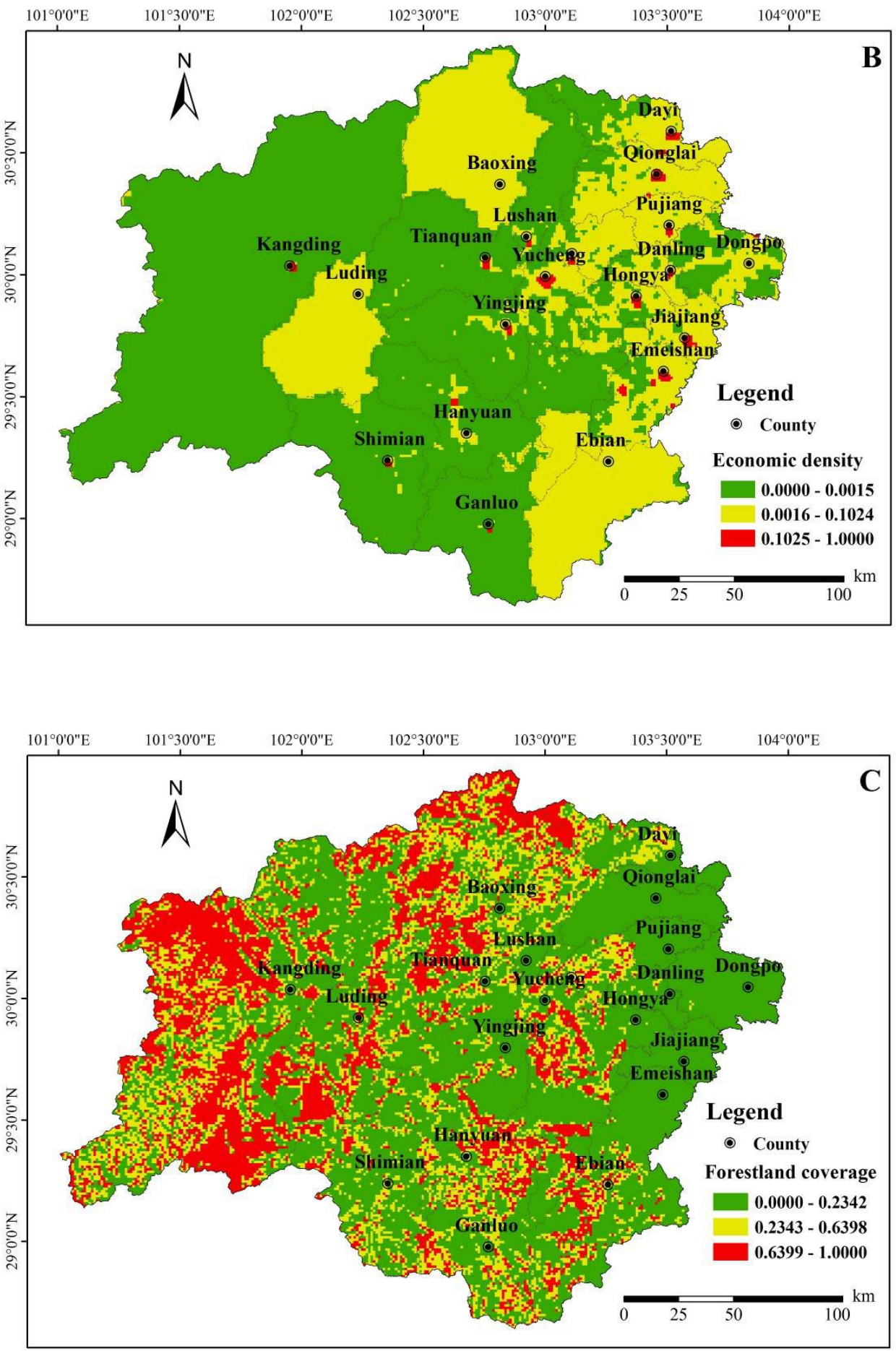

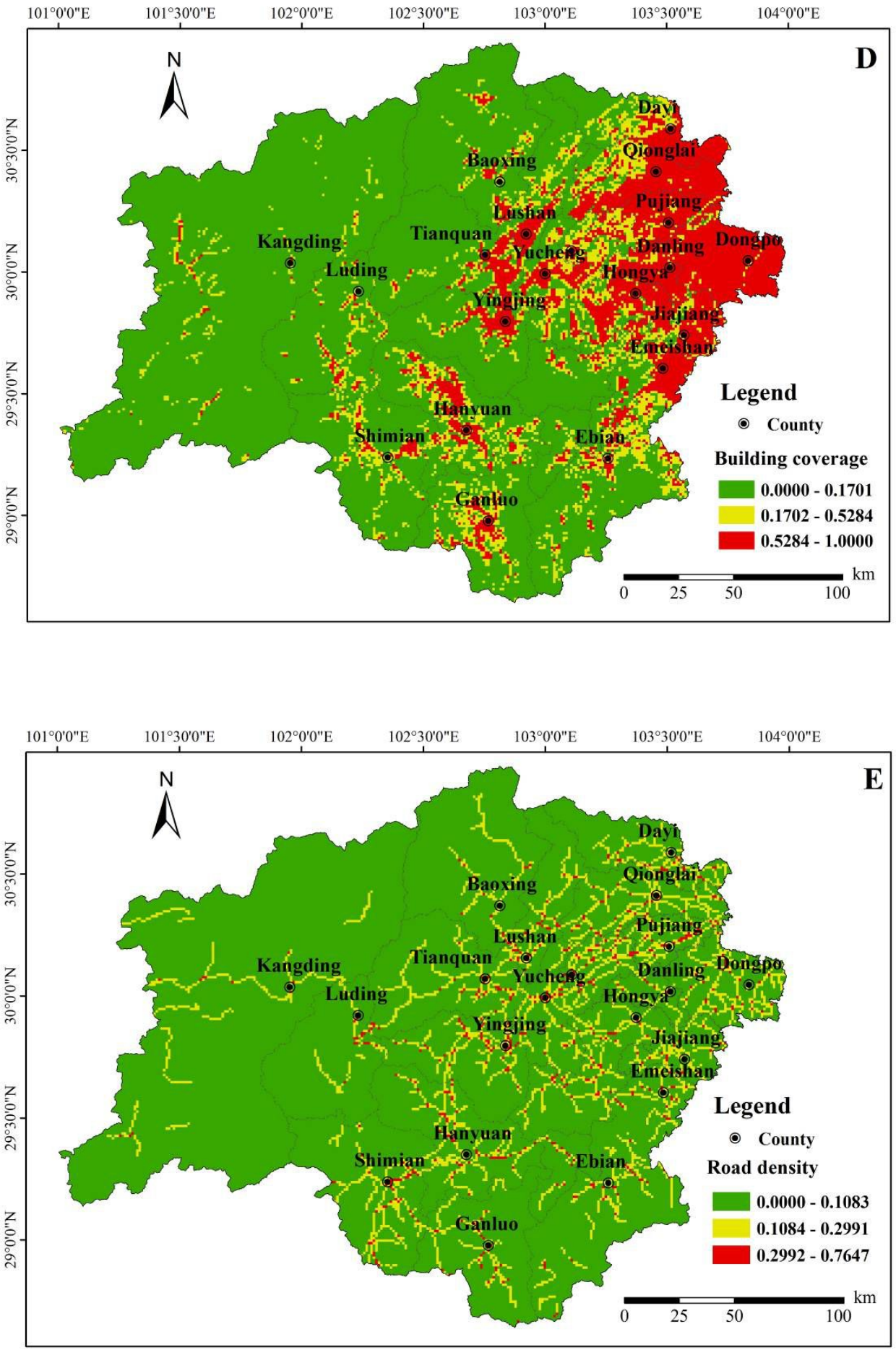


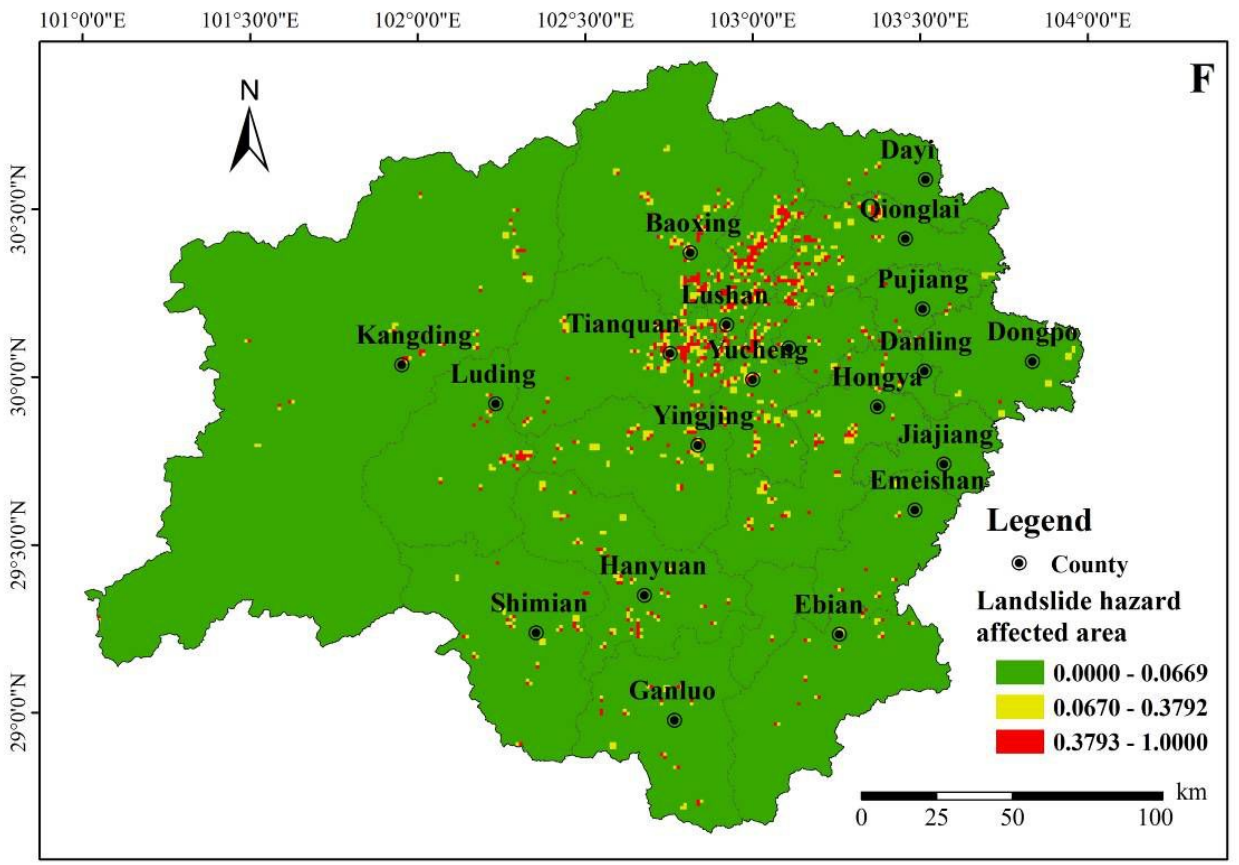

Fig.2. Vulnerability factor distribution maps (obtained by normalizing the extreme factor values)

(A. Distribution map of population density, B. Distribution map of economic density, C. Distribution map of forestland coverage, D. Distribution map of building coverage, E. Distribution map of road density, F. Distribution map of landslide hazard affected areas)
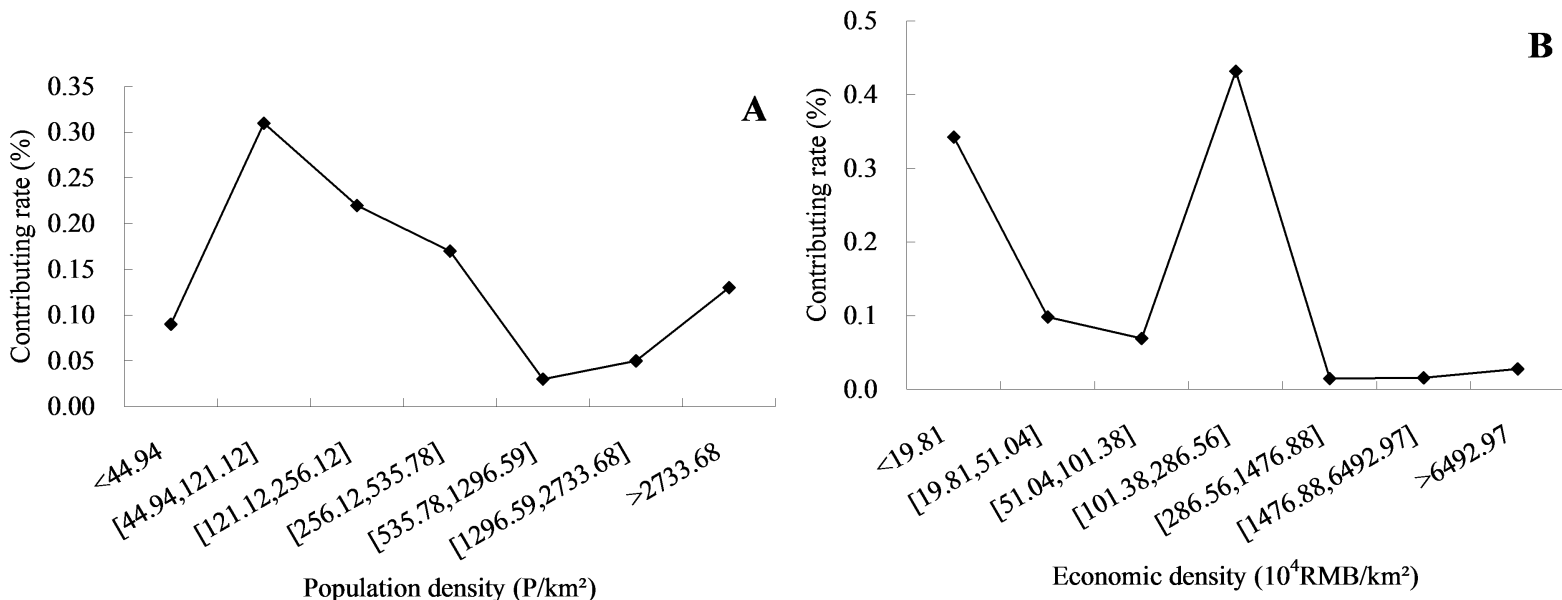

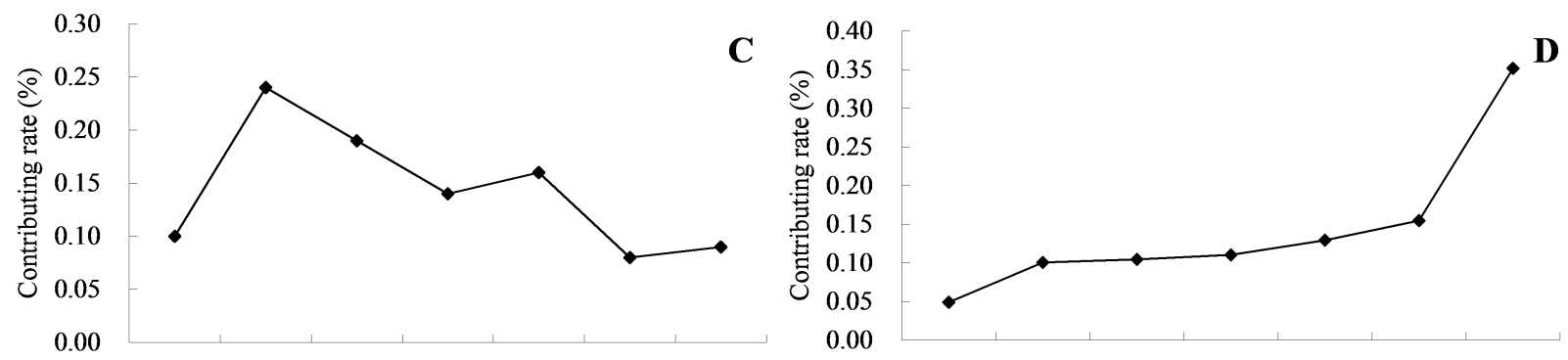

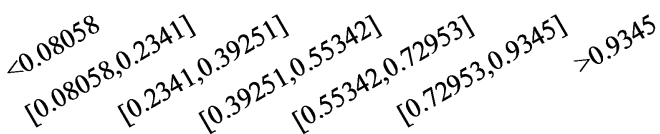

Forestland coverage (\%)
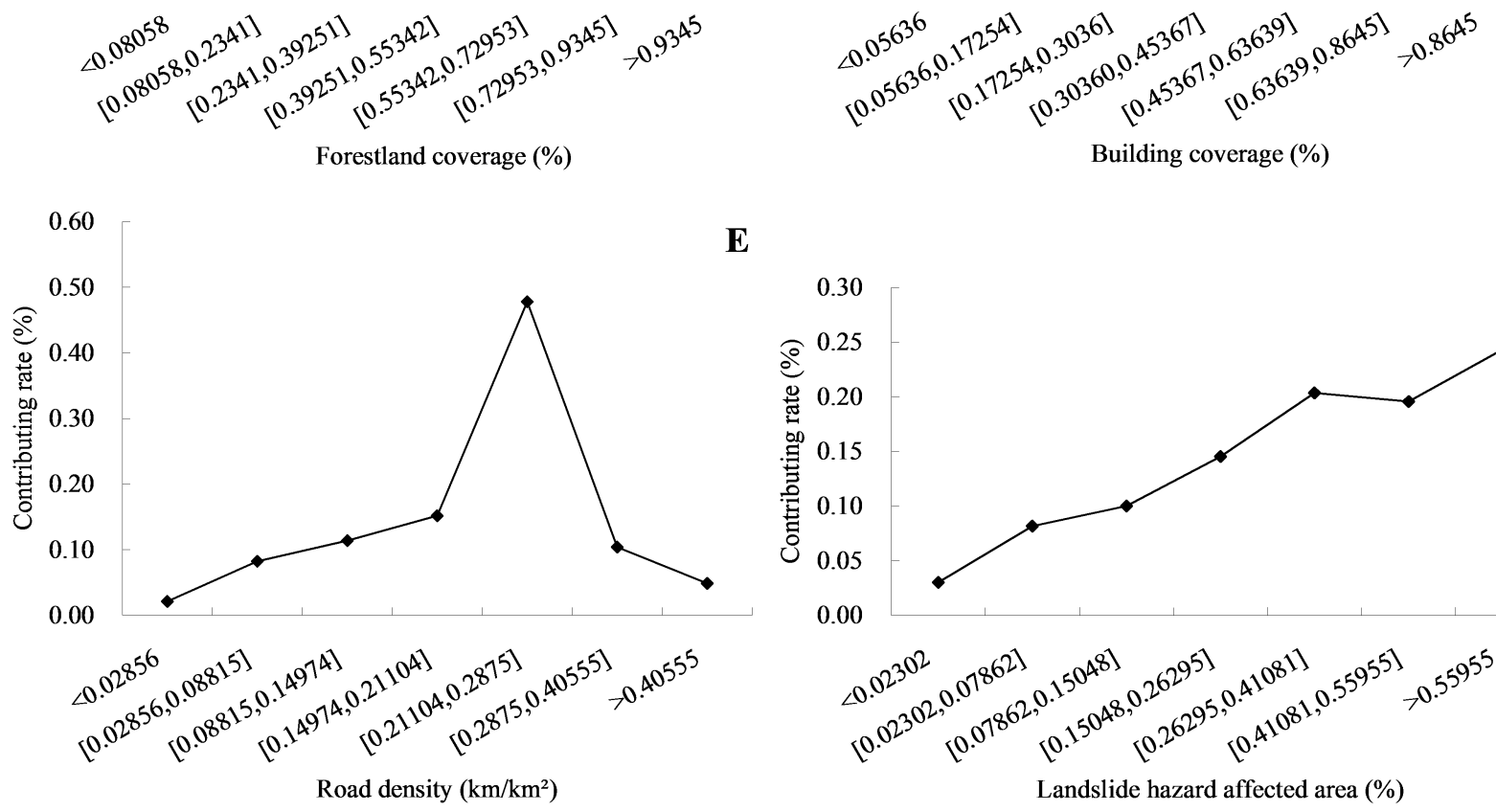

$\mathbf{E}$

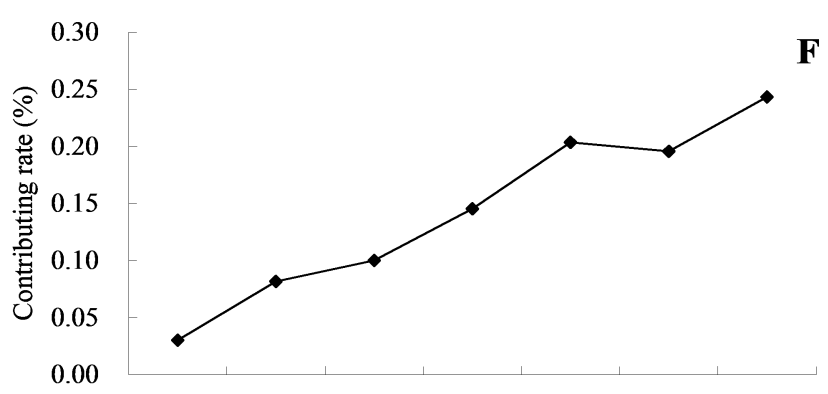

Fig.3. Contributing rate graphs of vulnerability factors to the landslide hazard vulnerability (A. Contributing rate of population density, B. Contributing rate of economic density, C. Contributing rate of forestland coverage, D. Contributing rate of building coverage, E. Contributing rate of road density, F. Contributing rate of landslide hazard affected areas)

Table 1. Weight assignment of vulnerability assessment indexes for Lushan earthquake-stricken areas

\begin{tabular}{ccccc}
\hline \multirow{2}{*}{ Index } & \multicolumn{3}{c}{ Self-weight } & \multirow{2}{*}{ Mutual weight } \\
\cline { 2 - 4 } & High & Middle & Low & 0.199 \\
\hline Population density & 0.620 & 0.372 & 0.008 & 0.188 \\
\hline Economic density & 0.644 & 0.340 & 0.016 & 0.176 \\
\hline Forestland coverage & 0.647 & 0.339 & 0.014 & 0.258 \\
\hline Building coverage & 0.635 & 0.351 & 0.014 & 0.124 \\
\hline Road density & 0.660 & 0.325 & 0.015 & 0.055 \\
\hline $\begin{array}{c}\text { Landslide hazard affected } \\
\text { areas }\end{array}$ & 0.650 & 0.347 & 0.003 &
\end{tabular}




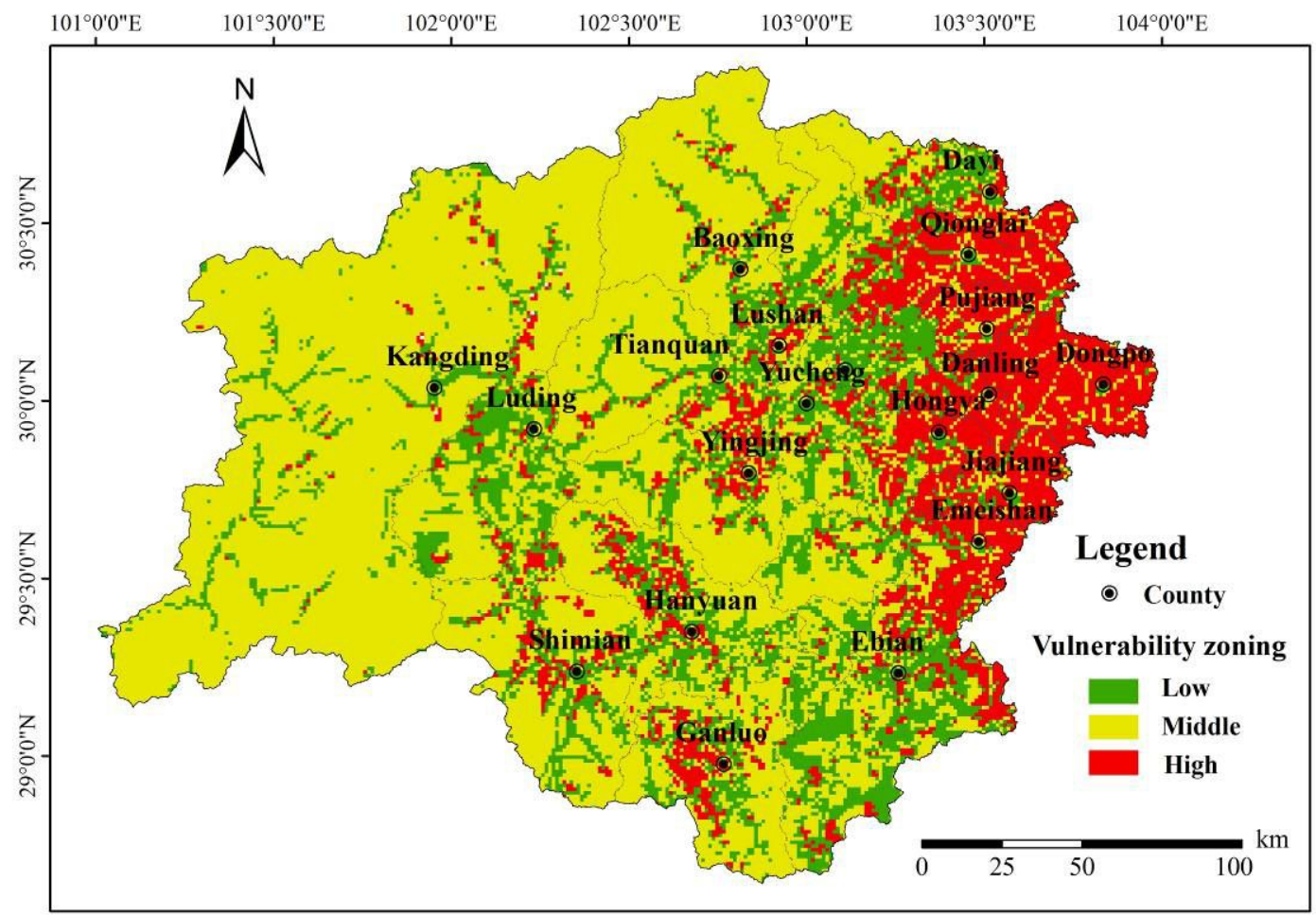

Fig. 4. Vulnerability assessment results map of landslide hazards in Lushan earthquake-stricken areas

Table 2. Vulnerability zoning results table of landslide hazards in Lushan earthquake-stricken areas

\begin{tabular}{ccccc}
\hline Zone & $\begin{array}{c}\text { Area } \\
\left(\mathrm{km}^{2}\right)\end{array}$ & $\begin{array}{c}\text { Area percentage } \\
(\%)\end{array}$ & $\begin{array}{c}\text { Landslide } \\
\text { hazards (number } \\
\text { of sites })\end{array}$ & $\begin{array}{c}\text { Landslide hazard } \\
\text { site percentage } \\
(\%)\end{array}$ \\
\hline High vulnerability zone & $7,666.98$ & 17.93 & 15 & 2.17 \\
\hline Middle vulnerability zone & $26,316.97$ & 61.54 & 39 & 5.65 \\
\hline Low vulnerability zone & $8,778.98$ & 20.53 & 616 & 89.28 \\
\hline $\begin{array}{c}\text { Lushan earthquake-stricken } \\
\text { areas }\end{array}$ & $42,762.93$ & 100 & 690 & 100 \\
\hline
\end{tabular}

However, most of the landslide hazard affected areas distribute in this scarcely populated zone, due to its underdeveloped economy and scattered buildings. The positive correlation between the distribution of landslide hazard affected areas and the intensity of human engineering activities shows that the middle vulnerability zone is recently under high-speed development, and that the engineering activities have a great impact on the ecological environment.

(2) It can be seen by contrasting the landslide hazard distribution with the vulnerability results that the high, middle, and low vulnerability zones take up 17.93\%,
$61.54 \%$, and $20.53 \%$ of the total area; while the landslide hazard site percentage is $2.17 \%, 5.65 \%$, and $89.28 \%$ respectively. The reason lies in the saturated socioeconomic development of middle and high vulnerability zones, and the initiate stage of the low. Intensive human engineering activities there have caused severe damages to the social environment and triggered lots of secondary geological hazards like landslides.

\subsection{Discussion}

Limited by the author's knowledge structure and inadequate assessment data, the landslide hazard 
vulnerability assessment in this study lacks accuracy. There is still plenty of room for further research and discussion at many aspects.

(1) Regarding the aspect of data, it is difficult to acquire certain data of the study area due to unpredictable elements. This hinders the completeness of assessment indexes, leaving out building structure types, building use modes, and other information. Moreover, excessive workload makes it impossible to extract some other data within a short period of time; for instance, the land use data. The poor data completeness is thus caused, leaving a gap between theory and practice.

(2) Regarding the aspect of assessment scale, the $1 \mathrm{~km} \times 1 \mathrm{~km}$ landslide hazard vulnerability assessment is carried out in this paper with the support of GIS Grid Technology. Despite of the improved accuracy of vulnerability assessment, the socioeconomic data are still obtained in the basic unit of counties. In a way, the data accuracy is again lowered.

Contrasted with the field survey ones, the computing and zoning results of landslide hazard vulnerability assessment in this paper basically correspond with the actual situation of Lushan earthquake-stricken areas. Therefore, such assessment method based on GIS and Contributing Weight Overlay is feasible.

\section{Acknowledgements}

The study was financially supported by the National Natural Science Foundation of China (Grant No. 41371185 and 41101164), the key project of Education Department of Sichuan Province (Grant No. 13ZA0160) and the project of Science and Technology Department of Sichuan Province (Grant No. 2013HH0057).

\section{References}

G. S. Yang, Y. F. Shi, C. Zhang, H. T. Liang, Assessment of vulnerable scope to environmental change in Jiangsu coastal plain, Acta Geographica Sinica. 4(55) (2000) 385-394.

S. L. Cutter, B. J. Boruff, W. L. Shirley, Social vulnerability to environmental hazards. Social Science Quarterly, 84 (2) (2003) 242-261.

B. Wisner, P. Blaikie, T. Cannon, I. Davis, At risk: natural hazards, people's vulnerability, and Disasters, Second revised edition. (Routledge, New York, 2004).

I. Burton, R. Kates, G. White, The environment as hazard, Second edition. (The Guilford Press, New York, 1993).
Y. C. Zhang, Risk analysis and benefit evaluation of prevention and control on mud-rock flow disaster of Dongchuan City in Yannan Provinve, Journal of Geological Hazards and Environment Preservation. 6(I) (1995) 25-34.

T. Jiang, P. Z. Xu, Community vulnerability assessment-a new approach for natural disaster studies, Discovery of Nature. 15(56) (1996)45-50.

Y. Guo, Review of the research on hazard vulnerability, Journal of Catastrophology. 20(04) (2005)92-96.

C. Tang, J. Zhang, C.H. Zhou, Y. B. Tie, Vulnerability assessment of urban debris flow hazard, Journal of Catastrophology. 20(2) (2005) 11-17.

X. L. Liu, D. W. Mo, Risk assessment on debris flow (Sichuan Science and Technology Publishing House, Xinjiang Sci-Tech and Public Health Press, 2003).

J. X. Gao, Nakamura Takehiro, Y. Z. Pan, et al., Flood vulnerability assessment: a case study of Dongting Lake area (China Environmental Science Press, Beijing, 2004).

E. D. Alexander, Vulnerability, in Encyclopedia of Environmental Science, eds. E. D. Alexander and R.W. Fairbridge (Netherlands: Springer, Dordrechet, 1999) pp.663-664.

E. D. Alexander, Vulnerability to landslides, in Landslide Risk Assessment. Eds. T. Glade, M.G. Anderson and M.J. Crozier (UK: John Wiley \& Sons, Chichester, 2005) pp.175-198.

R. Fell, Landslide risk assessment and acceptable risk, Can Geotech. 31(1994) 261-272.

R. Fell, K.K.S. Ho, S. Lacasse, E. leroi, A framework for landslide risk assessment and management, in Proceedings of the International Conference on Landslide Risk Management (London, Taylor \& Francis Ltd, 2005) pp.3-25.

R. Fell, D. Hartford, Landslide risk management. in Landslide Risk Assessment, eds. D.M. Cruden and R. Fell (A.A. Balkema Publisher, Rotterdam, 1997) pp.51-109.

E. M. Lee, D.K.C. Jones, Landslide risk assessment (ICE Publishing, London, 2004).

T. Glade, Vulnerability assessment in landslide risk analysis, Die Erde. 134(2004) 123-146.

R. C. llorens, J. M. Vilaplana, J. Corominas, J. Altimir., J. Amigó, Rockfall risk management in high-density urban areas, The Andorra experience, in Landslide Hazard and Risk, eds. T. Glade, M. G. Anderson, M. J. Crozier (John Wiley, 2005) pp.675-698.

F. Leone, J. P. Aste', E. Leroi, Vulnerability assessment of elements exposed tomass-movement: working toward a better risk perception, in Landslides, eds. Senneset (A. A. Balkema Publisher, Rotterdam, 1996) pp.263-269.

G. G. Msilimba, P. A. Holmes, Landslide hazard assessment and vulnerability appraisal procedure: Vunguvungu / Banga catchment, Northern Malawi, Natural Hazards. 34(2005) 199-216. 
M. Galli, F. Guzzetti, Landslides vulnerability criteria: a case study from Umbria, Central, Italy Environ Manage. (40)4(2007) 649-665.

X. Q. Xiang, Regional Landslide Hazard Assessment and Risk Management, Doctor Thesis (Chengdu University of Technology, 2005).

F. C. Dai, C. F. Lee, Y. Y. Ngai, Landslide risk assessment and management: an overview, Engineering Geology. 64(1) (2002) 65-87.

Mejia Nanarro M. and Wohl E. E., Geological hazard and evaluation using GIS: Methodology and model applied to Medellin. Colombia Bulletin of The Association of Engineering Geologists. XXXI (4) (1994) 459-481.

M. M. Leiba, F. Baynes, G. Scott and K. Granger. Quantitative landslides risk assessment of Cairns, Australia Geomechanics: Journal and News of the Australian Geomechanics Society..37(3) (2002)1-13.

M. Wise, G. Moore, D. F. Vandine, Technical terms and method, in Landslide Risk Case Studies in Forest Development Planning and Operations. eds. M. Wise, G. Moore, D. F. Vandine (B.C., Ministry of Forests, Forest Science Program, Abstract of Land Management Handbook, 2004) pp.13-26.

Y. P. Wu, H. M. Tang, W. Jiang, Landslide hazard risk prediction system for the new Badong county seat based on GIS, Hydrogeology and Engineering Geology. (S1)(2003) 117-121.

J. J. Jin, Regional landslide disaster risk assessment methods, Journal of Mountain Science. 25 (2) (2007)197-201.

L. L. Shi, J. P. Qiao, Vulnerability Evaluation on Regional Landslides Based on GIS and Contribution Weight Superposition Approach, Journal of Catastrophology. 24(3) (2009) 46-50.

M. T. Ding, K. H. Hu, Susceptibility mapping of landslides in Beichuan County using cluster and MLC methods, Natural Hazards, 70 (1) (2014) 755-766.

M. T. Ding, Z. L. Cheng, Q. Wang, Coupling mechanism of rural settlements and mountain disasters in the upper reaches of Min River, Journal of Mountain Science.11 (1) (2014) 66-72.

M. T. Ding, M. Heiser, J. Hübl, S. Fuchs, Regional vulnerability assessment for debris flows in China - a CWS approach, Landslides. (2015) DOI: 10.1007/s10346-015-0578-1.

C. Miao, M. T. Ding, Social vulnerability assessment of geological hazards based on entropy method in Lushan earthquake-stricken area, Arabian Journal of Geosciences.

(2015)

DOI: 10.1007/s12517-015-1945-x.

J. P. Qiao, C. Y. Wu, H. L. Tian, Contribution rate research of stratum to landslide growth of Yunyang-Wushan segment in Three Gorges Reservoir Region, Chinese Journal of Rock Mechanics and Engineering. 23 (17) (2004) 2920-2924.
M. Wang, J. P. Qiao, C. Y. Wu, Regional landslide danger assessments based on GIS and the root factor contributing weight model: a case study of the Wanzhou District, Chongqing City, China, Geological Bulletin of China. 27 (11) (2008)1802-1809.

M. Wang, J. P. Qiao, Application of contributing weights model in regional landslides hazard assessment, The Chinese Journal of Geological Hazard and Control. 21 (1) (2010) 1-6.

C. Miao, M. T. Ding, J. Wang, P. Zhou, The distributing characteristics and cause of secondary mountain hazards in Lushan earthquake-stricken area, Resources and Environment in Yangtze Basin. 23 (11) (2014) 1572-1579. 